\title{
Japanese Black Cattle with Ateliosis Showed Lower Insulin Responses during Glucose Tolerance Test
}

\author{
Masaki TAKASU'), Yasunori OHBA ${ }^{2}$, Youko HAGIWARA ${ }^{2)}$, Iwai HOSODA ${ }^{2)}$, Naohito NISHII ${ }^{1}$, Katsuya KITOH $^{2}$, \\ Kiyoshi MIYAZAWA ${ }^{2)}$ and Hitoshi KITAGAWA ${ }^{2)}$ \\ ${ }^{1)}$ Department of Veterinary Medicine, United Graduate School of Veterinary Sciences, Gifu University, and ${ }^{2)}$ Department of Veterinary \\ Medicine, Faculty of Applied Biological Sciences, Gifu University, 1-1 Yanagido, Gifu, 501-1193, Japan
}

(Received 18 August 2004/Accepted 4 March 2005)

ABSTRACT. In order to determine insulin secretability and glucose utilization, a glucose tolerance test was performed in ateliotic cattle of 2 paternal strains; MHO and HSK cattle. MHO and HSK cattle showed different endocrine patterns in our previous study. Area under the insulin concentration curves (insulin-AUC) in the ateliotic cattle were significantly lower $(122.3 \pm 59.4 \mathrm{ng} \cdot \mathrm{min} / \mathrm{m} l \mathrm{and} 99.2 \pm 24.8$ $n \mathrm{~g} \cdot \mathrm{min} / \mathrm{m} l$ for MHO and HSK cattle, respectively) than the control cattle $(420.2 \pm 175.2 n \mathrm{~g} \bullet \mathrm{min} / \mathrm{m} l)$. These low insulin responses to GTT may have an influence on growth retardation in MHO and HSK cattle. KEY WORDS: ateliosis, cattle, GTT.

J. Vet. Med. Sci. 67(6): 635-637, 2005

Insulin is the sole hormone involved in glycogenesis and regulating the glucose supply to cell. This hormone controls not only the source of energy for living cells, but is also a crucial element in the growth of animals $[3,9]$. Thus, secretory patterns of insulin and glucose utilizations may be reflected in the growth pattern of animals. We conducted a glucose tolerance test (GTT) of paternal strains of ateliotic cattle [MHO-paternal and HSK cattle (MHO and HSK, respectively)] to determine the pedigree-specific differences in insulin secretory patterns and glucose utilization. These two strains of cattle had strain-specific endocrine patterns (unpublished data). MHO cattle showed high plasma growth hormone $(\mathrm{GH})$ concentrations in contrast to low serum concentrations of insulin-like growth factor-1 (IGF1 ), and low serum thyroid hormones and cortisol concentrations. HSK cattle demonstrated the same secretory patterns as $\mathrm{MHO}$ cattle, although they showed much more moderate concentration.

Ten ateliotic cattle were used for the present study: 4 HSK and $6 \mathrm{MHO}$ cattle, respectively; 3 males (1 MHO and 2 HSK cattle), 3 females (MHO cattle), and 4 castrated males (2 MHO and HSK cattle). Five cattle with normal growth patterns were selected as controls. Their ages ranged from 3 to 27.5 months at trial. A glucose solution (50\% glucose, Terumo Corp, Tokyo, Japan) with a bolus dose rate of $1.0 \mathrm{ml} / \mathrm{kg}$ was injected into the jugular vein [2]. Blood samples were collected immediate before, and at 5 , $15,25,35,45,60,90$, and $120 \mathrm{~min}$ after the glucose injections. Plasma insulin concentrations were determined at 0 , $5,15,25,35,45,60$, and 120 min using an enzyme immunoassay kit (Mercodia Bovine Insulin ELISA, Uppsala, Sweden). The area under the insulin concentration curve (insulin-AUC) was calculated to determine insulin secre-

\footnotetext{
* Correspondence to: Kitagawa, H., Department of Veterinary Medicine, Faculty of Applied Biological Sciences, Gifu University, 1-1 Yanagido, Gifu 501-1193, Japan.
}

tion. In addition, the half-life $\left(\mathrm{T}_{1 / 2}\right)$ of the glucose concentration was calculated. Scheffe's F-test was used to determine the significance of differences, and $\mathrm{P}<0.05$ was considered to be significant.

Clinical signs and results of laboratory screenings (Table 1) indicated that all cattle were in relatively good physical condition or had mild diarrhea and/or pneumonia, which clinically have little influence on growth. Cattle had good or slightly low appetite during our observation. Moreover, no cattle suffered renal tubular dysplasia [5] or bovine viral diarrhea virus infection [6], which can be causes for ateliosis.

The ateliotic cattle showed lower insulin secretions than the control cattle (Fig. 1). Insulin-AUCs were significantly lower in the ateliotic cattle than in the control cattle. Baseline glucose concentrations in the HSK cattle were significantly lower than in the control cattle, and those in the MHO cattle tended to be lower than in the control cattle. The maximum plasma glucose concentration in HSK cattle was lower than both MHO and control cattle. MHO cattle decreased plasma glucose concentrations a bit more gradually than the control cattle. Compared to the control and the HSK cattle, $\mathrm{T}_{1 / 2}$ of the glucose for the MHO cattle tended to be prolonged, but there was no statistical difference (Table 2).

In the body, energy is derived from nutrients in two different ways. One way is through storage (anabolism), and the other way is through elimination (catabolism). Insulin, an anabolic hormone, is an indication of glucose regulation. Ateliotic cattle in the present study demonstrated significantly lower insulin secretion than the control. These low insulin secretions during hyperglycemia are not suitable conditions for fattening and growth [7]. A low sensitivity to insulin secretion during hyperglycemia indicates an anabolic deficiency, which was observed in ateliotic cattle in the present study, and this might be one of the primary or 
Table 1. Results of the clinical screening

\begin{tabular}{lccc}
\hline \multirow{2}{*}{ Variable } & Control cattle $(\mathrm{n}=5)$ & MHO cattle $(\mathrm{n}=6)$ & HSK cattle $(\mathrm{n}=4)$ \\
\cline { 2 - 4 } & Mean $\pm \mathrm{SD}$ & Mean $\pm \mathrm{SD}$ & Mean $\pm \mathrm{SD}$ \\
\hline Erythrocyte $\left(\times 10^{4} / \mu l\right)$ & $1,002 \pm 121$ & $923 \pm 151$ & $1,000 \pm 175$ \\
Hematocrit $(\%)$ & $34.8 \pm 3.0$ & $28.2 \pm 1.3$ & $31.3 \pm 2.9$ \\
Leukocyte $(/ \mu l)$ & $8,100 \pm 1,431$ & $9,367 \pm 3,455$ & $6,000 \pm 346$ \\
Aspartate transaminase $(\mathrm{U} / l)$ & $85.8 \pm 70.1$ & $56.9 \pm 23.2$ & $64.8 \pm 11.9$ \\
Alkaline phosphatase $(\mathrm{U} / l)$ & $353.3 \pm 231.0$ & $288.6 \pm 158.8$ & $271.0 \pm 38.4$ \\
Urea nitrogen $(\mathrm{mg} / \mathrm{d} l)$ & $4.5 \pm 4.4$ & $11.1 \pm 7.0$ & $15.5 \pm 3.1$ \\
Creatinine $(\mathrm{mg} / \mathrm{d} l)$ & $1.1 \pm 0.0$ & $1.1 \pm 0.6$ & $1.0 \pm 0.2$ \\
Glucose $(\mathrm{mg} / \mathrm{d} l)$ & $88.5 \pm 4.4$ & $80.9 \pm 35.0$ & $82.3 \pm 21.0$ \\
Cholesterol $(\mathrm{mg} / \mathrm{d} l)$ & $99.0 \pm 19.2$ & $90.0 \pm 37.6$ & $64.0 \pm 11.0$ \\
Total protein $(\mathrm{g} / \mathrm{d} l)$ & $6.8 \pm 0.7$ & $5.3 \pm 2.1$ & $5.9 \pm 0.3$ \\
Albumin $(\mathrm{g} / \mathrm{d} l)$ & $2.8 \pm 0.2$ & $2.5 \pm 1.0$ & $2.9 \pm 0.2$ \\
Calcium $(\mathrm{mg} / \mathrm{d} l)$ & $10.7 \pm 0.4$ & $8.6 \pm 4.1$ & $10.6 \pm 0.7$ \\
Inorganic phosphorus $(\mathrm{mg} / \mathrm{d} l)$ & $6.8 \pm 0.4$ & $5.7 \pm 2.4$ & $7.0 \pm 1.7$ \\
\hline
\end{tabular}

SD: Standard deviation. There were no significant differences among the three groups.
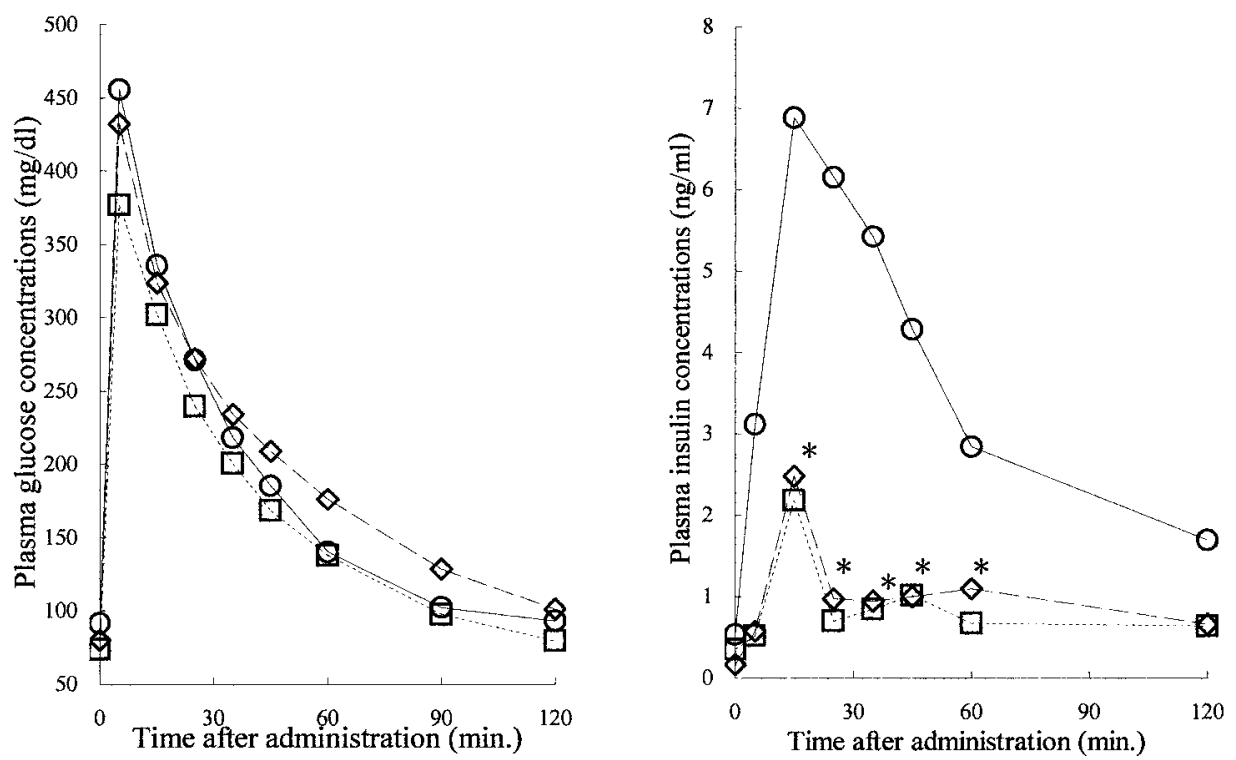

Fig. 1. Plasma glucose (left) and plasma insulin (right) concentrations during glucose tolerance test. $\bigcirc$ : Control cattle $(\mathrm{n}=5), \square$ : MHO cattle $(\mathrm{n}=6), \square$ : HSK cattle $(\mathrm{n}=4) . *$ : An asterisk denotes a significant difference from the control cattle $(\mathrm{p}<0.05)$.

secondary causes for growth retardation. There is the possibility that the ateliotic cattle might have a low sensitivity for insulin secretion during hyperglycemia, although the insulin itself might be normal.

Catabolic hormones, such as $\mathrm{GH}$, might restrict insulin effects in MHO cattle [8]. An increased GH concentration causes a peripheral glucose resistance through the inhibition of glycogen synthesis and glucose oxidation [1]. Hormones interact with each other. MHO cattle showed greater $\mathrm{GH}-$ AUCs than HSK and the control cattle, although other catabolic hormones, such as thyroid hormones and cortisol, were not higher than that of either the control and the HSK cattle (unpublished data). Even though decreased rates of plasma glucose concentration might be reflected in the renal elimination rates of glucose, there may be a possibility that low insulin secretions and peripheral insulin resistances caused by higher $\mathrm{GH}$ concentrations had an influence on the prolonged $\mathrm{T}_{1 / 2}$ of glucose concentrations in MHO cattle. However, other factors might exist.

Since the energy source of ruminant animals hardly rely on exogenous glucose, a glucose tolerance test might scarcely reflect the physiological insulin secretability and glucose utilization in ruminant animals. It has been reported that insulin secretability in ruminants could possibly demonstrate material-specific secretory patterns reflecting physical conditions $[3,4,7]$. Therefore, further studies are needed to determine insulin secretability stimulated by different materials in ateliotic cattle. 
Table 2. Results of the glucose tolerance test

\begin{tabular}{llccc}
\hline \multirow{2}{*}{ Substance } & \multicolumn{1}{c}{ Parameter } & Control cattle $(\mathrm{n}=5)$ & MHO cattle $(\mathrm{n}=6)$ & HSK catle $(\mathrm{n}=4)$ \\
\cline { 3 - 5 } & & Mean $\pm \mathrm{SD}$ & Mean $\pm \mathrm{SD}$ & Mean \pm SD \\
\hline \multirow{3}{*}{ Insulin } & Baseline concentration $(\mathrm{ng} / \mathrm{m} l)$ & $0.54 \pm 0.16$ & $0.16 \pm 0.15^{*}$ & $0.35 \pm 0.30$ \\
& Maximum concentration & $6.88 \pm 3.55$ & $2.48 \pm 1.50^{*}$ & $2.18 \pm 1.40^{*}$ \\
& $(\mathrm{ng} / \mathrm{m} l)$ & $420.2 \pm 175.2$ & $122.3 \pm 59.4^{*}$ & $99.2 \pm 24.8^{*}$ \\
\hline \multirow{3}{*}{ Glucose } & Insulin AUC $(\mathrm{ng} \cdot \mathrm{min} / \mathrm{m} l)$ & $94.8 \pm 6.8$ & $80.0 \pm 13.1$ & $70.5 \pm 1.9^{*}$ \\
& Baseline concentration $(\mathrm{mg} / \mathrm{d} l)$ & $480.4 \pm 63.4$ & $432.0 \pm 103.8$ & $369.8 \pm 93.0$ \\
& Maximum concentration & $38.3 \pm 12.8$ & $50.2 \pm 12.3$ & $37.6 \pm 15.3$ \\
\hline
\end{tabular}

SD: Standard deviation. AUC: Area under the concentration curve. *: An asterisk denotes a significant difference from the control cattle $(\mathrm{p}<0.05)$.

We would like to thank Mr. N. Yamazumi of the Veterinary Hospital of Gifu University for his technical assistance and care of the animals. This work was supported in part by a Grant-in-Aid (No. 15380214) for Scientific Research from the Ministry of Education, Culture, Sports, Science and Technology of the Government of Japan.

\section{REFERENCES}

1. Hull, K. L. and Harvey, S. 1999. J. Endocrinol. 163: 165-172.

2. Kaneko, J. J. 1997. pp. 63-68. In: Clinical Biochemistry of Domestic Animals, 5th eds. (Kaneko, J. J., Harvey, J. W., and Bruss, M., L. ed), Academic Press, California, U.S.A.

3. Manns, J. G. and Boda, M. 1967. Am. J. Physiol. 212: 747755.
4. Manns, J. G., Boda, M. and Willes, R. F. 1967. Am. J. Physiol. 212: 756-764.

5. Ohba, Y., Kitagawa, K., Okura, Y., Kitoh, K. and Sasaki, Y. 2001. Vet. Rec. 149: 115-118.

6. Radostits, O. M., Blood, D. C. and Gay, C. C. 1994. pp. 993 1008. In: Veterinary Medicine, 8th ed., Bailliere Tindall, London.

7. Sano, H., Arai, H., Takahashi, A., Takahashi, H. and Terashima, Y. 1999. Can. J. Anim. Sci. 79: 309-314.

8. Sartin, J. L., Cummins, K. A., Kemppainen, R. J., Marple, D. N., Rahe, C. H. and Williams, J. C. 1985. Am. J. Physiol. 248: E108-114.

9. Styne, D. 2000. pp. 163-200. In: Basic \& Clinical Endocrinology, 6th ed. (Greenspan, F. S. and Gardner, D. G. ed.), The McGraw-Hill Companies, Inc., San Francisco, U.S.A. 